\title{
A MARCHA LENTA DA AMÉRICA LATINA NO SÉCULO XXI
}

Amado Cervo ${ }^{1}$

\section{Introdução}

A última década do século XX caracterizou-se por duas mudanças profundas nos países da América Latina. O velho paradigma desenvolvimentista, esgotado pela inflação, pela estagnação econômica e pela exaustão do Estado como agente econômico preponderante, cedeu lugar ao paradigma neoliberal, abraçado com entusiasmo por dirigentes e sociedades latino-americanos. Sem quebra institucional, houve, portanto, uma mudança econômica e outra política, dimensões que, somadas, perfazem a mudança do paradigma histórico. Ao transitar para o século XXI, a região passa por nova mudança paradigmática: exauriu-se no espaço de uma década a dinâmica neoliberal, e os países da América Latina mergulharam no século XXI à procura de outro destino.

As forças profundas externas pouca influência tiveram como causalidades determinantes das duas transições. Os fatores propulsores da mudança devem ser buscados, sobretudo, no interior da região.

A transição para o neoliberalismo, na passagem dos anos I980 para I990, sofreu por certo influência externa maior que a dispersão observada no século XXI. Para induzir o neoliberalismo, contribuíram o fim da Guerra Fria, a crise do comunismo e dos socialismos, o enfraquecimento do Estado, a convergência liberal no traçado de regras e regimes da nova ordem internacional, ordem carregada então pelo fenômeno da globalização econômica. A América Latina embarcou nessa evolução de alcance quase sistêmico. Política e diplomacia em escala global passaram, com efeito, a apoiar novos processos produtivos para a indústria, as finanças internacionais e os serviços.

Que destino buscam os países da América Latina e do Caribe no século XXI, após as experiências neoliberais? Quais são os elementos propulsores

I Professor da Universidade de Brasília e do Instituto Rio Branco. E-mail: amado.l.cervo@ gmail.com 
de que se servem para alcançá-lo? Quais os objetivos, as estratégias de ação e os resultados? Quais os ritmos verificados nesse movimento?

Para responder aos problemas postos à presente análise, o caminho da interpretação e da construção do argumento, ou seja, a metodologia, conduz nosso olhar pelos seguintes campos de observação: a) nexo entre região e conjuntura global; b) identificação de tendências políticas e econômicas regionais permanentes; c) falhas internas estruturais, políticas e econômicas; d) o caráter da marcha lenta latino-americana em termos comparativos globais.

A base conceitual e empírica sobre a qual a análise se assenta será buscada em nossos estudos anteriores e complementada por abundante literatura disponível sobre as relações internacionais da América Latina, cujos grandes intérpretes são arrolados na bibliografia; os dados, sobretudo estatísticos, serão colhidos em boletins, documentos ou relatórios publicados regularmente por institutos de pesquisa latino-americanos. Tanto a documentação como nossas interpretações, que induzem conhecimento novo e novos conceitos, refletem, portanto, o conhecimento e o pensamento internacionalista latino-americano.

\section{A América Latina na ordem global}

Três notáveis instituições reuniram pesquisadores nos meados da segunda década do século XXI com o intuito de avaliar a evolução da América Latina. Organização para a Cooperação e Desenvolvimento-OCDE, Corporação Andina de Fomento-CAF e Comissão Econômica para América Latina e Caribe-CEPAL visavam com esse trabalho não somente o diagnóstico econômico, político e social, mas igualmente as estratégias de ação que produziram ou travaram resultados. Estavam preocupados, pois, com a marcha regional.

Entre 2003 e 20I2, a região cresceu em média $4 \%$ ao ano, apesar da crise financeira internacional de 2008-2009. Em certa medida, andou por si, contudo seu crescimento nesses anos foi favorecido pelo aumento do comércio mundial, bem como dos preços das matérias primas que exportava. Esses dois estímulos externos deixaram de incidir favoravelmente desde então. $\mathrm{O}$ destino regional, que vinha sendo dinamizado por tais estímulos externos como também pelo aumento da demanda interna resultante da inclusão social, refugiou-se em mãos próprias nos meados da segunda década do século. A resposta à nova situação não foi adequada e a América Latina entrou em fase de declínio, de ritmo lento ou estagnado, evidenciando mais uma vez a escassez sobre a dinâmica regional de fatores internos ou a sua ausência. 
De que forma a América Latina poderia ter mantido seu ritmo de crescimento e modernização, tirando forças de dentro de suas capacidades? Em quais estratégias de desenvolvimento reside a falha? Essas questões serão consideradas no andamento da presente análise.

Lembremos, previamente, outros indicadores. Entre 2000 e 20II, segundo dados fornecidos pelos pesquisadores acima referidos, as exportações de commodities da América Latina passaram de 40\% para 60\% sobre o total. Preços e volumes cresciam simultaneamente. A orgia do dinheiro conjuntural produziu a indolência operacional: importação de manufaturados, de bens de capital e desaceleração da indústria local. Commodities viajando para fora, comodismo instalando-se nas sociedades, sob olhares complacentes e passivos dos dirigentes. Onde está, pergunta-se, a causalidade do declínio? De onde agem os fatores estruturantes que comandam a evolução: dos condicionamentos favoráveis ou desfavoráveis de fora ou dos defeitos estratégicos de dentro?

Os povos latino-americanos, não os governos, responderam. Depois que programas bem sucedidos de inclusão social produziram efeitos regionalizados, aumentando o bem-estar e diminuindo a desigualdade social em toda parte, uma nova classe média surgiu e fez ouvir sua voz em manifestações de massa que se espalharam pelo subcontinente. Os povos exigiam que os dirigentes das esquerdas que levaram ao poder provessem a sociedade de serviços públicos de qualidade, empregos de qualidade, modernização e elevação da produtividade das indústrias e dos serviços. Ao que parece, bradavam em vão, visto que os provedores de políticas seguiam com a política do vazio $^{2}$.

Desde 2009, o crescimento do Produto Interno Bruto-PIB da região América Latina e Caribe, segundo dados da Comissão Econômica para a América Latina e Caribe-CEPAL, evidencia tendência de baixa muito grave, em termos comparativos globais. Enquanto o crescimento mundial alcançou $2,4 \%$ em 2013 e $2,6 \%$ em 20I4, nesse último ano a região cresceu apenas I,I\%, o menor crescimento desde 2009. O baixo dinamismo regional deve-se àquela escassez de estratégias adequadas, sobretudo nos grandes países da região, como Brasil, Argentina, Venezuela e México. Durante o segundo mandato de Dilma Rousseff, o Brasil assume as rédeas do declínio latino-americano, seguindo uma Venezuela em crise estrutural (Cervo e Lessa 20I4). Na América do Sul, a queda do comércio exterior, nos meados da segunda década, atingia $-2,7 \%$. Queda devida à escassez de estratégias destinadas à superação do conjunto de vulnerabilidades de uma região que se satisfaz com

2 Perspectivas Económicas de América Latina 2014. Informe produzido conjuntamente por OCDE, CAF e CEPAL. 
exportações de matérias primas, mesmo quando seus preços declinavam no mercado global. Causa e efeito da escassez de estratégias, o fluxo de Investimentos Diretos no Exterior- IDEs para a região, poderoso motor de melhorias dos setores manufatureiro, de serviços e mesmo de matérias primas, de emprego e renda para o povo, também situa América Latina e Caribe em péssima posição global: crescimento global de IDEs de ıı\%, crescimento regional de 2,5\% em 20I3 (Cepal 2015).

Seguindo a tendência da política do vazio, aquela em que o Estado não faz praticamente nada, a queda livre do Brasil influi desastradamente sobre a região, em razão de seu porte econômico. Três indicadores caracterizam essa queda. Depois de registrar o crescimento máximo de 7,5\% em 20I0, o crescimento negativo de $-3,8 \%$ de seu PIB em 20I5, o menor índice desde o início dos anos I990, segundo estatísticas do Instituto Brasileiro de Geografia e Estatística-IBGE, e uma massa de mais de nove milhões de desempregados no início de 2016 , segundo dados do mesmo IBGE, colocam o país somente atrás da Venezuela em mau desempenho econômico. Ademais, verifica-se em 2015 uma queda de I4.I\% dos investimentos. O choque desses indicadores sobre a opinião pública, ou seja, sobre empresários e investidores estrangeiros e brasileiros, sobre o consumidor e mesmo sobre o pequeno comércio, visto que a queda do PIB se deve sobretudo à queda de produção e consumo de bens industriais, destrói a confiança no Estado. Mesmo porque o Estado é ferido por escândalo de corrupção sem precedente nas últimas décadas, derivado de sua poderosa empresa Petrobras. A conjuntura econômica se deteriora nas últimas três décadas, segundo o jornal Valor Econômico, sem que os dirigentes se disponham a reorientar as estratégias de desenvolvimento. A vizinhança lança olhares atônitos em direção àquele que deveria servir de exemplo e carregar o crescimento regional, mas que mergulha em crise econômica, política e moral'3.

\section{Tendências regionais permanentes}

A identidade latino-americana constitui fenômeno complexo, sobre o qual raramente os estudiosos ousam discorrer. Preferimos nesse texto identificar elementos comuns às nações latino-americanas, os quais, de certo modo concreto e objetivo, compõem, em nosso entender, a identidade regional. Tais elementos correspondem a tendências históricas. Isolamos quatro tendências no século XXI, como elementos constitutivos do perfil identitário regional,

3 Valor Econômico, São Paulo, Edição de 4 de março de 20ı6. Essa edição descreve o perfil da crise conjuntural da economia brasileira 
visto que expressam fenômenos sociais com notável grau de permanência, supostamente decorrentes da natureza comunitária. São eles: democracia, preocupação com o social, zona de paz e integração. São componentes que, por certo, enriquecem o perfil identitário regional, conferindo-lhe em termos comparativos globais, um lugar privilegiado. Não são elementos perfeitos ou puros, porém, traços prevalecentes, considerada a dimensão regional. O impacto desse perfil identitário sobre as relações regionais, bem como sobre a inserção internacional da região e de cada nação, acentua ainda mais a singularidade latino-americana em termos comparativos. Esse impacto sobre as relações internacionais constitui nosso objeto de análise, e não propriamente a essência de cada um dos componentes referidos.

A democracia, entendida como governos resultantes do processo eleitoral e legitimados pela vontade popular manifesta por meio do voto, expande-se desde os anos I980. Nas décadas anteriores, disputavam o controle do poder regimes políticos autoritários, militares ou não, com regimes democráticos. O liberalismo da década de 1990 estimulou a purificação do regime, com a vitória da democracia. Destarte, no século XXI, a democracia será o regime político regional latino-americano, uma tendência permanente.

A preocupação com o social, isto é, com a distribuição mais igualitária possível do bem-estar, que outras regiões, como a do Estado do bem-estar europeu implementou de modo exemplar e em intensidade incomparável em termos globais, também se converteu em tendência permanente e regional na América Latina. Com a agonia dos regimes autoritários nos anos I980 não irrompeu a preocupação com o social, apesar de evoluir-se com firmeza rumo à democracia. Tanto assim é que, na década posterior, a última do século XX, emerge com força o neoliberalismo, mais próximo do indivíduo, de sua liberdade de ação e de sua promoção. O social estaria longe, então, da preocupação dos dirigentes e das lideranças sociais, como ocorria na fase anterior da disputa entre regimes autoritários e democráticos.

A opinião pública percebeu que não convinha manter essa tendência de valorização do indivíduo sobre a valorização do social, na virada do século XX para o XXI. Por meio do voto, substituiu os dirigentes e os partidos políticos por outros de matiz ideológica distinta, propensos a introduzir em pé de igualdade, ao lado da democracia, a preocupação com o social como preocupação política. As estratégias de ação do Estado modificaram-se substancialmente, fenômeno que uma abundante literatura especializada chamou de ascensão das esquerdas. Duas tendências conjugam-se, destarte, para integrar o perfil da identidade latino-americana: democracia e preocupação social.

O balanço da ascensão das esquerdas sobre o bem-estar das sociedades é diferenciado entre as nações latino-americanas. Por vias muito diver- 
sas, mediante estratégias de ação distintas, os dirigentes de esquerda tiveram em mente a distribuição da riqueza e do bem-estar. De regional, observa-se a generalização em toda parte dos chamados programas sociais, correspondentes, grosso modo, à politização da preocupação com o social. Para financiá-los, nações extraíam recursos de produtos da natureza, como petróleo e gás, minérios e outros; nações extraíam recursos do orçamento; nações adotavam outras modalidades de extração de recursos. Todas, porém, exibiam seus programas de inclusão social. Umas nações acoplavam seus programas à promoção da educação e do desenvolvimento, outras não, exibiam programas distributivistas sem exigência, propensos a fomentar a indolência coletiva. Outras acoplavam os programas sociais à manutenção dos partidos ou dirigentes de esquerda no poder. Cabe ao estudioso analisar as experiências nacionais e avaliar a imensa diversidade de resultados dos programas sociais latino-americanos no século XXI. De qualquer modo, como havia ocorrido na transição do neoliberalismo para as esquerdas na virada do século, por volta de 2015 assistia-se ao retorno de partidos e dirigentes conservadores. Seria uma crítica da opinião eleitoral à má condução dos programas sociais? Ao que parece, a democracia conjugava-se com o desempenho positivo ou viciado dos regimes políticos. Imbuída agora de exigências que cobravam do poder, além da redistribuição da riqueza, desempenho condizente com as necessidades econômicas do progresso tecnológico, da melhoria dos serviços públicos, do emprego, da educação e saúde. Enfim, requisições de sociedades cujo desenvolvimento, complexo, permanecia em marcha lenta, em horizonte longínquo.

Se o leitor imaginar que democracia e preocupação com o social conjugaram-se e produziram resultados concretamente benéficos para a inclusão social dos povos latino-americanos, mas que também contribuíram para perturbar o processo de desenvolvimento, entendido como progresso tecnológico, modernização empresarial e crescimento econômico, estará pensando como o autor da presente análise. De fato, o modo como a América Latina gerenciou democracia e preocupação com o social preparou a região para um resultado pernicioso, a marcha lenta.

Persigamos, contudo, os outros dois componentes da identidade regional: zona de paz e integração. Esses dois outros parâmetros também se conjugam entre si, a exemplo de democracia e inclusão social, com os quais imbricam-se, ademais, de modo nuclear. Identidade nacional ou regional, que os filósofos nos permitam afirmar, constitui complexo fenômeno social composto de variáveis interdependentes. Destarte, nossas quatro variáveis se conjugam.

A criação da zona de paz sul-americana e latino-americana assenta 
sobre um longo e sólido percurso, aberto pela tradição histórica de pacifismo que prevaleceu na região desde as independências do início do século XIX. Esse espírito pacifista, bem expresso então por Simon Bolívar, para guiar as relações internacionais dos países da região, impõe-se, historicamente, apesar de algumas guerras no período de formação dos Estados nacionais ou em razão da delimitação das fronteiras. O espírito pacifista aflora em ig67, quando se firma o Tratado de Tlatelolco, ratificado pelas trinta e três nações de América Latina e Caribe. Por meio dele, antes do Tratado de Não Proliferação Nuclear da ONU, de I970, a região proscreve a fabricação e o uso de armas nucleares. Depois, suas diplomacias, especialmente a do Brasil, tornam-se muito ativas para a obtenção do tratado global na ONU, bem como no seio de sua Conferência do Desarmamento. Não satisfeitos com as garantias globais estabelecidas na ONU, Brasil e Argentina submetem desde I99I seus programas nucleares à inspeção tanto da Agência Internacional de Energia Atômica-AIEA quanto da Agência Brasileiro-Argentina de Contabilidade e Controle de Materiais Nucleares. Os dois países haviam avançado mais pela pesquisa e domínio da tecnologia nuclear e pretendiam assegurar seu uso unicamente para fins pacíficos.

Convém aprofundar o nexo entre o conceito zona de paz e o fenômeno da integração. O processo de integração posto em marcha nos anos I980 encampou o propósito de reforçar e institucionalizar a zona de paz, não apenas na aparência material e humana, mas na inteligência política regional. Em uma primeira fase, o processo avançou na área da América do Sul, já que o México fez sua opção estratégica pela integração com o Norte. Obtém-se, como marco importante da evolução desse processo, a assinatura do Tratado Constitutivo da União das Nações Sul-Americanas-UNASUL, em Brasília, em 2008, o qual entrou em vigor em 20II. Com uma estrutura organizacional presidida por dois conselhos superiores, o Conselho dos Chefes de Estado e o Conselho dos Ministros de Relações Exteriores, a UNASUL conta, ademais, entre seus órgãos de gestão mais relevantes, com o Conselho Sul-Americano de Defesa. Dele deriva o Centro de Estudos Estratégicos, instalado em Buenos Aires em 20II, com o fim de formular e regionalizar uma doutrina sul-americana de segurança. Em sequência, em 20I5, tem início o funcionamento da Escola Sul-Americana de Defesa, com sede em Quito, sob a direção do Professor de Relações Internacionais da Universidade de Brasília, Antônio Jorge Ramalho da Rocha. Sua finalidade consiste em formar quadros civis e militares capacitados em Defesa, à base daquela doutrina sul-americana, cujo escopo síntese é posto pelo conceito de zona de paz, a ser consolidada nas relações regionais e incrustrada na política exterior da região.

A construção da zona de paz, erguida em uma primeira fase, como vi- 
mos, na área da América do Sul, retornou a seu fundamento latino-americano e caribenho, que a História sugeria. Durante a Cúpula de Havana de 20I4, os trinta e três países que compõem a Comunidade dos Estados Latino-Americanos e Caribenhos-CELAC criaram a Zona de Paz da América Latina e Caribe. O espírito original que pairava sobre a inteligência política regional conduz a Cúpula a decisões cada vez mais precisas, que estabelecem os contornos e o alcance do conceito de zona de paz: a região permanece sem armas nucleares, elimina a intervenção em assuntos internos de outros Estados, fixa a solução pacífica de contenciosos entre seus países, enfim, proscreve a guerra. Uma formulação diametralmente oposta à que preside a geopolítica e o comportamento da Organização do Tratado do Atlântico Norte-OTAN. Tão incisivo manifesta-se esse espírito original em torno do pacifismo que a CEL$\mathrm{AC}$ fora criada em $20 \mathrm{O}$ o como alternativa à Organização dos Estados Americanos-OEA, na qual os Estados Unidos exerciam influência e não aceitavam os princípios da zona de paz. Ademais, a zona de paz latino-americana, por esforço sobretudo brasileiro, estende-se ao Atlântico sul. Em I986, uma resolução da ONU estabelece a Zona de Paz e Cooperação do Atlântico Sul, logo integrada por 24 países banhados por esse oceano às margens da África Ocidental e da América do Sul oriental. Reuniões ministeriais regulares, atualmente anuais, revitalizam a organização e vigiam a área, com o objetivo de realizar o propósito maior dessa expansão da zona de paz latino-americana, que é o de manter as potências militares de outras regiões fora da área.

Desse modo, consolida-se a zona de paz como tendência histórica, nas mentes e nas práticas. Brota essa tendência da tolerância e da convivência de diferenças étnicas e culturais e carrega pesada carga civilizacional. O terceiro componente fulgura, pois, como estrela da identidade latino-americana. Seu vínculo com a democracia é posto, na América do Sul, primeiramente, em 2009 , pela proscrição do uso da força para solução de conflitos entre Estados da região e pela instituição de um mecanismo de confiança mútua em matéria de defesa e segurança; posteriormente, em 20ıo, pelo Protocolo Adicional ao Tratado Constitutivo de 2008 , protocolo firmado em reação rápida diante de crises políticas em Honduras e Equador. Assim nasceu a chamada Cláusula Democrática da UNASUL. Ela foi acionada em alguns casos, sendo o mais relevante sua forte atuação na Venezuela, desde 20I4, para preservar resultados de eleições democráticas ameaçados pelo governo dito bolivariano.

$\mathrm{O}$ quarto e último componente da identidade latino-americana e caribenha, a qual, segundo interpretação do presente texto, é composta por tendências históricas permanentes, é a integração. De modo mais perceptível do que sucede com a zona de paz, esse componente se expande e reflui, como respiração de um corpo vivo. Com efeito, zona de paz penetra no corpo 
regional e o impregna com melhor dominação do que integração. São duas tendências, diríamos, diferenciadas na profundidade.

Já que os marcos cronológicos do processo de integração foram indicados acima, convém proceder a um balanço de concepções e resultados que definam a natureza da integração como tendência.

Nos anos I950, os presidentes de Brasil e Argentina achegaram-se e conceberam um primeiro ensaio de integração a começar pelos dois países maiores da América do Sul (Vidigal 200I). Os regimes militares que se espalharam pela América do Sul, nas décadas seguintes, deram ao processo formas que alguns analistas consideram deformadas, porém a ideia de integração permanece presente em âmbito regional. Foi necessário esperar pela redemocratização do subcontinente, nos anos I980, para assistir ao retorno da integração com novo alento, como produto mental de alcance operacional. Os presidentes de Argentina e Brasil, Raúl Alfonsín e José Sarney, por volta de 1985 , conceberam audacioso projeto de integração regional, a começar pelos dois países. Com ênfase econômica, esse projeto visava uma estratégia de desenvolvimento capaz de colocar os países rumo à maturidade sistêmica: por meio dele, as nações tinham como propósito apoio mútuo para elevar a produtividade, implementar o comércio entre si, modernizar a organização empresarial, favorecer a inovação tecnológica, em suma, alcançar o desenvolvimento avançado.

O projeto brasileiro-argentino concebido nos anos I980 sofrerá desvios de percurso. Nos anos I990, ao tempo do neoliberalismo, que contamina economia e política na América Latina, o processo de integração abandona o propósito da modernização econômica e converte-se em integração comercial. Por certo, fez aumentar o comércio regional e até mesmo criou comércio novo. Apesar de haver inspirado, de certo modo, projeto similar ao Norte, com o Tratado de Cooperação Amazônica de I978, aquele projeto brasileiro-argentino dos anos I980 não contribuiu para o reforço da produtividade e para a inovação tecnológica, como imaginavam Sarney e Alfonsín. Mesmo havendo voltado miradas brasileiras para o lado da Venezuela, como se a experiência do Prata devesse reproduzir-se ao norte, dando à integração dimensão regional segura.

No século XXI, toma impulso a integração da América do Sul, com a criação da Iniciativa para a Integração da Infraestrutura da América do Sul-IIRSA (2000) e, como vimos acima, com a criação da UNASUL. A ideia de modernização econômica ressurge, porém, a integração enfrenta dois novos entraves. Barreiras alfandegárias perturbam a operacionalidade, especialmente a partir dos governos de Nestor e Cristina Kirchner na Argentina, que conduzem o país ao regresso histórico da época do desenvolvimentismo, 
promovendo a introspeç̧ão econômica, o protecionismo e a reestatização, enfim, o isolamento internacional. Por outro lado, a América Latina toma o rumo da dispersão e irá restringir o alcance da integração à esfera política e de segurança. Diversos modelos de desenvolvimento, uns mais liberais, outros mais nacionalistas ou introspectivos, outros mais abertos ao capital e empreendimentos externos proliferam, ao lado de distintos modelos de inserção internacional, uns que promovem a interdependência da era da globalização, outros que se fecham e isolam a nação. O Mercosul, instalado em I99I, mantém-se como mola propulsora do processo de integração, rumo à criação da UNASUL. Contudo, outras organizações reúnem nações em blocos distintos, como a Comunidade Andina de Nações, a Aliança do Pacífico, a Aliança Bolivariana para os Povos de Nossa América-ALBA, o Mercado Comum Centro-Americano e a adesão do México ao North American Free Trade Agreement. A Comunidade de Estados Latino-Americanos e Caribenhos-CELAC, que abrange todo o subcontinente, pouca expressão econômica ostenta.

Em suma, o processo de integração latino-americano mantém viva a tendência histórica, porém deixa de produzir resultados com capacidade de propulsão do desenvolvimento moderno, perseguindo o caminho das economias avançadas tradicionais ou mesmo da economia chinesa no presente. Os países da região não se alçam no século XXI à competitividade sistêmica, como esperavam lideranças políticas anteriores. Maior economia regional, o Brasil enfrenta entraves na vizinhança, oriundos do malogro da IIRSA e da introspecção econômica. Considerada embrião da integração, precisamente em razão de seu foco econômico, a IIRSA foi saudada com entusiasmo quando de sua criação em 2000. Desde 20II, segundo o Instituto de Pesquisas Econômicas Aplicadas-IPEA, converte-se em fórum de debates sobre integração física. Deixa, pois, de reconhecer seu fracasso operacional de uma década, durante a qual bem poucos projetos regionais concebidos chegaram a termo, e desloca sua operacionalidade para o discurso político, agora no âmbito do Cosiplan. Este Conselho de Planejamento da UNASUL exibe, em 20I4, uma carteira de 580 projetos no valor de I6I,4 bilhões de dólares. Até 20I4, segundo o IPEA, a IIRSA teria concluído apenas I7\% dos projetos, correspondentes a I2\% do valor do investimento previsto. Dados mais recentes do INTAL, informam que em 2015 havia 593 projetos na carteira do Cosiplan, correspondentes ao valor de i 82 bilhões de dólares. Até então, teriam sido concluídos II5 projetos. O déficit de infraestrutura nacional e regional, com raras exceções, prossegue evidenciando falhas elementares ${ }^{4}$.

Em 20I5, segundo dados da Confederação Nacional da Indústria do

4 INTAL. Conexión Intal, Boletim, 4 de março 20I6. Ver puclicações do IPEA referidas na bibliografia. 
Brasil, esse país deixava de vender cerca de I, 5 bilhões de dólares aos vizinhos, em razão da precariedade e insuficiência dos transportes regionais. Preso às regras do Mercosul, ademais, o Brasil não busca mercados por meio de acordos de livre comércio com outras regiões, contentando-se com a vizinhança. Seus capitais e empresas, contudo, tomam o rumo de mercados de fora da área, de forma crescente desde 2006, quando a introspecção econômica na vizinhança passa a espantá-los. O Brasil promove, destarte, a internacionalização da economia nacional como a grande inovação estratégica introduzida no século XXI.

Podemos concluir: o maior e quase único resultado concreto do processo latino-americano e caribenho de integração é o entendimento político, por certo um bem precioso, que alimenta e faz brilhar ainda mais a estrela da identidade regional, a zona de paz; sob o aspecto econômico e do desenvolvimento, os entraves à integração são tais que prolongam como resultado palpável a marcha lenta da região.

\section{À espera da inovação}

Os países da América Latina carecem no século XXI de estratégias propulsoras do processo de desenvolvimento, em intensidade adequada para elevar a região ao nível sistêmico avançado e mantê-lo. Por certo, conquistas relevantes foram alcançadas pelos governos de esquerda, como o parágrafo anterior evidencia, mas um longo caminho ainda se descortina no horizonte. Além do entendimento político regional, legado de longo fôlego histórico e resultado maior da integração, o século XXI assistiu à generalização dos programas de inclusão social. A redução da desigualdade social, entendida como exigência ética, impulsionou o desenvolvimento sustentável, como demonstra a CEPAL. Por outro lado, economia, política e meio ambiente representam variáveis vinculadas, como revela o tipo de desenvolvimento agregado à política regional desde a conferência Rio+20 de 20I2. Com efeito, sem competência de gestão, os ganhos na área social desse agregado podem não se perpetuar, podem comprometer o desenvolvimento sustentável (Cepal 20I5b).

A desigualdade social diminuiu, sem extinguir-se, contudo, a pobreza. Nova classe média emergiu por toda parte. Já a desigualdade entre as nações não se modificou no mesmo grau da desigualdade nas sociedades nacionais. Tudo isso, curiosamente, demanda inovação política e econômica, sem o que a região poderá perder os benefícios econômicos da inclusão social e ficar à mercê do retrocesso. Ou terá seu ritmo entravado, como ocorreu e já se registrou acima, por volta de 20I5. Quando irá a América Latina alcançar a 
maturidade sistêmica, onde chegaram outras regiões ou nações, em matéria de bem-estar do povo?

Examinemos as carências da América Latina sob os aspectos da inovação política e da inovação econômica. Examinemos, portanto, forças de obstrução do progresso.

Em primeira linha, vem à mente a falta generalizada de confiança da sociedade no Estado. Sem a motivação do Estado, que aponta ou induz oportunidades de movimento para agentes do progresso como capitais e empresas do país e do exterior, gerando expectativas otimistas, a modernização, o aumento da riqueza, a inovação tecnológica, em suma, a elevação do nível de renda dos cidadãos não avança em ritmo e abrangência adequados. Essa nova conduta do Estado como tendência de longo fôlego, que conquista a confiança da sociedade porque exerce uma função logística de apoio a suas lideranças e à realização de suas expectativas, modalidade que chamamos de Estado logístico, foi a condição para as nações avançadas poderem atingir o nível de bem-estar e maturidade econômica e social. Os governos de esquerda latino-americanos vislumbraram esse novo paradigma de conduta do Estado, porém, alguns países importantes minaram a nova funcionalidade do Estado com vícios que foram destruindo a confiança. O regresso ao velho desenvolvimentismo, em consequência de má gestão, parece haver contaminado a inteligência política de governos e destruído a confiança das forças da sociedade no Estado. Mediante retorno do protecionismo, centralização decisória, aumento da burocratização, reestatização de empresas e outras estratégias de ação similares em seus efeitos, alguns governos afugentaram investimentos internos e do estrangeiro. Isso ocorreu na Venezuela, na Argentina, na Bolívia, no Equador, bem como em outras partes, em dose e modalidades próprias. Ocorreu no Brasil, desde a ascensão de Dilma Rousseff ao poder, em 20II, quando o país entra em declínio, deixando de ser um país emergente segundo avaliações internas e internacionais. Investimentos produtivos diminuíram, o desemprego atingiu onze milhões de cidadãos e o crescimento econômico tornou-se negativo, com retração do PIB de -3,8\% em 20I5, à frente apenas da Venezuela do bolivarianista Nicolás Maduro, sucessor de Hugo Chávez. Nesses países, onde a conduta dos dirigentes viciou-se, o Estado logístico foi cerceado em sua função de estabelecer a confiança entre as partes, Estado e sociedade. Nos países andinos e no México, onde os governos não regrediram às modalidades de conduta do paradigma desenvolvimentista, isto é, não adotaram o retrógrado neodesenvolvimentismo, os nefastos efeitos econômicos e sociais foram menores.

A inovação política esperada na América Latina reside, pois, no diálogo entre Estado e sociedade, capaz de restabelecer a confiança necessária à 
propulsão das forças do desenvolvimento.

Em segundo lugar, a América Latina carece de inovação econômica. Nos anos I990, o neoliberalismo consertou de certo modo vícios acumulados pelo paradigma histórico do desenvolvimentismo, cujas estratégias haviam promovido o desenvolvimento, com boa eficiência, mediante dois impulsos: o externo, feito de capitais, empresas e tecnologias vindos de fora, voltados essencialmente para a industrialização e os serviços; o interno, feito de empresas estatais que atuavam sobretudo nas áreas de infraestrutura e de insumos básicos, como mineração e energia. As privatizações dos anos I990 representaram uma ruptura paradigmática, porém foram conduzidas à base de um erro estratégico: o núcleo forte das economias nacionais foi alienado a empreendimentos estrangeiros, desfazendo-se as nações do filé mignon econômico ou a ele renunciando, na expressão de empresários.

A América Latina possui imensa riqueza natural, correspondente a seus recursos minerais e agrícolas. O empreendimento agrícola andou por si e elevou a produtividade do setor ao nível tecnológico mais avançado em termos sistêmicos globais. Por outro lado, empresas mineradoras competem com esse progresso do empresariado agrícola. De modo geral, o caráter nacional desses empreendimentos é mantido. Entretanto, a exportação de produtos primários converteu-se em tentação constante de governos indolentes e carentes de visão tanto social quanto prospectiva. Ao invés de programar e orientar o empresariado para exploração industrial desses recursos, único meio de promover o emprego, a renda e o bem-estar das massas urbanas, bem como o desenvolvimento tecnológico, os governos com sua indolência acentuam o declínio global relativo da região (Unasur 20I4).

Com efeito, no século XXI, as esquerdas promoveram melhor distribuição de renda na sociedade, aumento do consumo e aparecimento de expressiva classe média. O erro estratégico da vez apresenta dois aspectos: a ausência de política de inovação tecnológica com o fim de restabelecer e reforçar o núcleo empresarial da nação e a quebra da confiança entre Estado e sociedade, a afugentar investimentos internos e externos. O fenômeno da internacionalização das economias latino-americanas, isto é, a expansão para fora de empresas nacionais, parecia induzir, no início do século XXI, a capacidade propulsora da modernização, mediante incorporação ao empreendimento nacional do progresso tecnológico que a penetração em cadeias produtivas globais requer. Poucos países aproveitaram a inserção de suas empresas em cadeias globais de valor para promover o progresso de suas indústrias. Esse sutil elemento propulsor da modernização, contudo, parece perder-se, convertendo-se a internacionalização de empresas latino-americanas em movimento autônomo, sem retorno, dados os entraves que se mantêm inter- 
namente, tais como falta de confiança no Estado, burocracia, carga tributária elevada, insuficiência de infraestrutura e ausência de políticas de inovação coordenadas entre Estado e sociedade.

A inovação econômica esperada na América Latina, reside, pois, na criação ou fortalecimento do núcleo empresarial nacional, mediante choque tecnológico com apoio mútuo e colaboração entre Estado e sociedade.

\section{A marcha lenta: comércio, investimento, crescimento}

Dirigentes ineficientes costumam deslocar para fora os males da gestão interna. Essa conduta é bem latino-americana, pois tornou-se comum em governos da região recorrer à crise financeira e econômica do mundo desenvolvido, de 2008 , ou a outras dificuldades externas, para explicar quedas do crescimento econômico e do emprego, do consumo e do investimento. De fato, como vimos acima, os males localizam-se em fatores internos: gestão pública de má qualidade técnica, falhas da própria economia, distância entre Estado e sociedade, insuficiência de inovação tecnológica, industrialização desprezada, integração sem resultado econômico. Na era da interdependência global, os fatores externos exercem causalidades, porém, no caso da marcha lenta latino-americana, eles agem apenas de leve. O ritmo regional é travado pelo declínio ou estagnação de algumas nações, sem ser compensado pelo bom desempenho ou pela liderança dinâmica de outras. A lerdeza se deve, essencialmente, à inexistência de núcleo empresarial nacional ou regional, operando em nível tecnológico sistêmico, de sorte a produzir impacto desenvolvimentista regional. Enquanto essa condição perdurar, a região não alcançará as economias avançadas, em termos de renda, bem-estar, nível e gênero de vida dos cidadãos.

Analistas de instituições latino-americanas, como CAF, BID, UNASUL, CEPAL e INTAL fornecem dados precisos e preciosos que fundamentam interpretações em bases objetivas. Que o leitor confira nas publicações regulares de tais instituições. Um desenvolvimento dispersivo e insuficiente trava a América Latina nas últimas décadas. A região perde relevância global comparativa, longe da dinâmica, por exemplo, dos emergentes asiáticos. Crises institucionais que exibem conduta errática de grandes e pequenos Estados, atraso tecnológico na área industrial e de serviços, estrutura econômica primária prevalecente e escassez de poupança e investimento próprios contribuem para travar o ritmo de crescimento. Cabe ao leitor concluir, diante da realidade exposta, se a causalidade principal do ritmo lento do crescimento latino-americano e caribenho concentra-se no Estado, em gestão 
irresponsável, carente de estratégias adequadas, ou então, como amiúde repetem dirigentes, em fatores externos coercitivos (Sánchez-Mais 20I5, Crespi et al. 20I4, Novelo 20I4).

Três indicadores - comércio, investimento e crescimento - expressam o conceito de marcha lenta da América Latina no século XXI. São mais incisivos a partir da segunda década do século, quando se observa a tendência de baixa no comércio exterior, nos volumes de investimento e nos índices de crescimento econômico.

Durante a primeira década do século XXI, América Latina e Caribe aumentam suas exportações em volume e valor, aumento verificado não somente nas exportações para fora da área, como também no comércio intrazona. As médias anuais de crescimento das exportações ficaram, por anos, próximas dos $15 \%$, portanto acima da média de crescimento do comércio mundial, próximo de II\%. As exportações regionais, ademais, estabeleceram-se em média levemente superior às exportações para fora da área, tendo seu pique entre 2004 e 2008 .

Contudo, os custos do transporte não prejudicam apenas as exportações brasileiras, fato acima revelado em documento da Confederação Nacional da Indústria do Brasil. Vinculam-se à precária infraestrutura regional e, por isso, representam talvez o maior obstáculo às exportações de América Latina e Caribe, segundo estudos da Revista Integración Q Comercio, publicados em 20I4. Quando uma retração econômica acentuada é observada no mundo, especialmente na China, durante a segunda década do século, não surpreende que estudos dados a conhecer pelo Monitor de Comércio e Integração do BID apresentem estatísticas preocupantes sobre a evolução do comércio exterior da região, cuja cesta é composta essencialmente por produtos básicos. Em 20I2, as exportações teriam aumentado apenas I, $2 \%$; queda de -0,2\% em 20I3. Em 20I4 a queda das exportações de bens da América Latina e Caribe corresponde a -2,8\%; -2,7 da América Latina. Os fatores que explicam esse declínio são internos e externos: concentração em produtos primários, queda da demanda e do volume exportado, como também dos preços internacionais (Giordano 20I5) ${ }^{6}$.

América Latina e Caribe exportam em maior escala produtos primários para fora da área e importam de fora máquinas e equipamentos, como também produtos industriais de consumo popular. Já o comércio intrazona apresenta perfil de melhor qualidade, visto que, sem excluir os produtos bási-

5 Ver Carta Intal: Comércio intrassul-americano: padrão exportador e fluxos intraindustriais, nov. 2013. Ver Monitor de Comércio e Integração do BID, 2015.

6 Ver do mesmo BID: Monitor de comercio e integración 2015. 
cos, compõe-se em maior medida de manufaturados. Automóveis, têxteis, plásticos e produtos químicos são importantes nos fluxos intrazona. Baixa vinculação desses fluxos com produtos oriundos de penetração em cadeias globais, o chamado comércio de mão dupla, aparece como outro fator negativo a qualificar o comércio regional, embora nesse âmbito tal fator seja menor intrazona do que no comércio para fora da área

De todo modo, o comércio exterior está diretamente ligado ao crescimento econômico dos países, por isso seu ritmo deve-se, essencialmente, ao elevado crescimento da América do Sul durante a primeira década, quando o crescimento brasileiro figura como motor regional, bem como ao elevado crescimento do comércio de manufaturados. Segundo o INTAL, as economias latino-americanas mantêm estreito vínculo de dependência com relação aos dois aspectos do comércio exterior, externo e intrazona. Durante a primeira década, de modo positivo; durante a segunda década, com agravamento a partir de 20I4, em razão da conjuntura mundial, de modo negativo. A balança do comércio exterior condiciona a arrecadação, portanto, o orçamento das nações; condiciona os montantes de investimento, a geração de emprego, enfim, o crescimento econômico.

É lugar comum na literatura especializada a crítica ao fato de a América Latina, especialmente os membros do Mercosul, não agirem no sentido de abrir mercados externos para suas exportações. A interdependência econômica global, que se denomina também de globalização econômica, consolida-se como tendência irreversível no século XXI. Comércio, finanças, fluxo de capitais, movimento empresarial, cadeias produtivas globais estão imbricados no fenômeno da globalização. Seu maior impulso vem de países emergentes. Os mais dinâmicos entre eles agruparam-se no bloco dos BRICS - Brasil, Rússia, Índia, China e África do Sul - com a clara finalidade de influir sobre a ordem internacional e modificar suas regras e regimes. Refluindo sobre si, as nações avançadas que comandavam a ordem anterior, evidenciando instinto de defesa de seus interesses, voltaram-se sobre si mesmas, tendo em vista a expansão de espaços econômicos que agreguem velhos mercados: União Europeia, acordo entre Estados Unidos e União Europeia, adesão do Japão a esse bloco de países avançados. A competição entre emergentes e desenvolvidos se estabelece, pois que o BRICS reage por sua vez, requerendo mais poder sobre órgãos internacionais que fixam regras no domínio das finanças e do comércio.

Uma primeira modificação se estabelece no seio do comércio internacional. Criada com o fim de estabelecer suas regras, as quais, em conjunto, definem o regime do comércio internacional, a Organização Mundial do Comércio-OMC, em razão da presença dos BRICS, deixa de cumprir sua 
função original com o avançar do século XXI. Os países avançados, sob iniciativa e liderança dos Estados Unidos, abrem outro caminho, de tal sorte que o regime do comércio internacional não se estabeleça mais em escala global, no seio da OMC. A partir de escalas regionais, quiçá, venha a alcançar escala global. Ao termo dessa competição, por volta de 2015 , conclui-se que o regime do comércio internacional, isto é, suas regras em escala prevalecente, seja fixado por acordos regionais de livre comércio. O novo regime deve ser objeto de muita atenção por parte de todas as nações, especialmente das emergentes e em desenvolvimento, porquanto os acordos regionais de comércio não apenas estabelecem regras ou facilitações comerciais, porém disciplinam investimentos, empréstimos, movimento empresarial e decisões políticas. Os acordos regionais de comércio passam a condicionar investimentos produtivos e crescimento econômico.

Quando o México se orientou para o Norte, aderindo ao NAFTA, quando os países andinos criaram seu bloco comercial com o fim de abrirem seu comércio ao Pacífico e a outros mercados, visavam adaptar-se a tal modificação da economia internacional. Enquanto isso, o governo brasileiro sofre críticas de lideranças empresariais por manter o pais fora dessa modificação da ordem internacional, sem abrir novos mercados e sem beneficiar-se da criação de novas e grandes áreas de livre comércio. As regras do Mercosul o impedem de acompanhar a evolução do comércio e por certo explicam em boa medida a queda brutal de seus investimentos produtivos e do crescimento econômico, em torno de 20I5. Com impactos internos sobre o desemprego, que vai além de onze milhões de trabalhadores, a renda, o consumo e o bem-estar. Com impactos externos sobre a vizinhança, onde estes mesmos indicadores econômicos e sociais entram em declínio. Com efeito, à medida que avança o século XXI, recua o ritmo de crescimento da América Latina: de $4 \%$ entre 2003 e 2008 , pouco mais de I\% em 20I4. Por razões regionais, que agregam a distância dos mercados globais à falha estrutural da economia que insiste em manter-se primária, quando demanda e preços de commodities tendem a cair (Mellado 20I5).

Esse quadro não se modifica com a ascensão da China sobre o comércio internacional. De fato, foram o dinamismo econômico chinês e sua demanda por produtos primários que estabeleceram a conexão comercial com a América Latina e, com ela, a tendência de substituir os Estados Unidos como primeiro parceiro comercial dos países latino-americanos. Com maior dificuldade do que ocorreu na relação com os Estados Unidos, esses países obtêm êxito em substituir a estratégia chinesa de exportar manufaturados para a América Latina e Caribe pela estratégia do investimento: ao invés de exportar, as empresas chinesas são instadas a produzir na região e investir, particular- 
mente, na melhoria da infraestrutura econômica regional (Ray et al. 20I5).

\section{Conclusão}

América Latina e Caribe entram em marcha lenta na segunda década do século XXI. São evidências principais a queda do comércio exterior, do investimento e do crescimento econômico. São consequências diretas o aumento do desemprego, a queda do consumo, bem como da produção industrial, da renda salarial e do bem-estar do cidadão. Marcha lenta desastrosa. Mesmo que dirigentes apelem a causalidades externas para o declínio econômico e social, os fatores prevalecentes que o determinam foram localizados no interior da região. A marcha lenta da América Latina e Caribe rumo ao desenvolvimento pleno é determinada no século XXI por uma soma de três causalidades principais, as quais, em parte, vêm agindo há décadas.

Uma primeira causalidade da marcha lenta reside na falta de confiança entre Estado e sociedade. No início do século XXI, o Estado desempenha nova funcionalidade na América Latina, semelhante à que o Estado exerceu historicamente nos países avançados: apontar ou induzir oportunidades para que capitais e empresas atinjam seus objetivos específicos e realizem seus interesses, produzindo bens e serviços, gerando emprego e renda e elevando o bem-estar do povo. Com o avançar do século, a má gestão pública compromete essa nova funcionalidade do Estado na América Latina e provoca a quebra da confiança entre Estado e sociedade, induzindo a retração das forças econômicas e o declínio geral, que denominamos de marcha lenta. Na região, a quebra da confiança resultou, com o avançar do século XXI, de crises políticas e institucionais graves, da elevada carga tributária, do inchaço do Estado, da burocratização, do desvio comportamental dos dirigentes de esquerda que se voltam a perpetuar o partido no poder e da ausência de estratégias adequadas à promoção do desenvolvimento.

Uma segunda causalidade da marcha lenta reside na escassez de inovação. Sem uma ação coordenada entre Estado e sociedade, a inovação tecnológica indispensável à elevação do nível de produtividade econômica ao patamar da produtividade sistêmica é travada. Tanto a região quanto as nações, embora em modalidade e intensidade variadas, carecem de estratégias de inovação tecnológica. Por isso, permanecem presas ao prevalecente caráter primário de suas economias, eternamente em desenvolvimento, longe da maturidade sistêmica global.

Uma terceira causalidade reside no truncado processo de integração. Esse processo contribuiu, por certo, para a construção da zona de paz region- 
al, que inclui o Atlântico Sul. A zona de paz latino-americana constitui a estrela que brilha no céu do mundo, uma preciosidade única e exemplar. Contudo, o processo latino-americano e caribenho de integração, voltado na primeira década do século para melhoria da infraestrutura regional, especialmente na América do Sul, perdeu eficiência, de tal sorte que a escassez tanto regional quanto nacional de infraestrutura persiste como entrave ao desenvolvimento e à modernização. Ademais, o processo de integração perdeu pelo caminho a estratégia de inovação tecnológica concebida originalmente por seus mentores.

\section{DOCUMENTAÇÃO}

Publicações de instituições regionais de pesquisa utilizadas para obtenção de dados estatísticos que fundamentam a interpretação. Principais instituições:

Banco Central do Brasil

Bando Interamericano de Desenvolvimento (BID)

Comissão Econômica para América Latina e Caribe (CEPAL)

Corporação Andina de Fomento (CAF)

Instituto Brasileiro de Geografia e Estatística (IBGE)

Instituto de Pesquisa Econômica Aplicada (IPEA)

Instituto para a Integração da América Latina e do Caribe (INTAL)

Faculdad Latinoamericana de Ciencias Sociales (FLACSO)

Fundação Getúlio Vargas (FGV)

\section{REFERÊNCIAS}

Almeida, Paulo Roberto de. 2013. Integração Regional: uma introdução. São Paulo: Saraiva.

Alvarez, S. T., e Bernal-Meza (orgs.). 20I2. Asuntos de América Latina. Bahia Blanca: El autor.

Alves, A. G. 20I4. Os Brics e seus vizinhos: investimento direto estrangeiro. Brasília: Ipea.

Baumann, Renato. 20I3. Integração regional: teoria e experiência latino-americana. Rio de Janeiro: LTC.

Baumann, Renato, e Oliveira, Ivan Tiago (orgs.). 20I4. Os Brics e seus vizinhos: comércio e acordos regionais. Brasília: Ipea. 
Bernal-Meza, R., e Quintanar, S. V. (orgs.). 20I2. Regionalismo y orden mundial: Suramérica, Europa, China. Buenos Aires: Grupo Editor Latinoamericano.

Bernal-Meza, R., e Saha, S. K. (orgs.). 2005. Economía mundial y desarrollo regional. Buenos Aires: Nuevohacer.

Bertonha, João Fábio. 2oII. Geopolítica, defesa e desenvolvimento. Maringá: Eduem.

Cepal. 20I5. Panorama económico y social de la comunidad de Estados Latinoamericanos y Caribeños 2014: Santiago: Cepal.

Cepal. 20I5b. Desarrollo social inclusivo: una nueva generación de políticas para superar la pobreza y reducir la desigualdad en América Latina y el Caribe. Santiago: Cepal. Santiago: Cepal

Cervo, Amado Luiz. 2013. Relações internacionais da América Latina: de 1930 aos nossos dias. São Paulo: Saraiva.

Cervo, Amado Luiz, e Rapoport, Mario (orgs.). 20I5. História do Cone Sul. Rio de Janeiro: Revan.

Cervo, Amado Luiz, e Lessa, Antônio Carlos. 20I4. "O declínio: inserção internacional do Brasil (20II-20I4)." Revista Brasileira de Política Internacional 57 (2): I33-I5I.

Couto, Leandro Freitas. 2013. Desenvolvimento, integração e assimetrias. Brasília: Fundação João Mangabeira.

Crespi, Gustavo et al. (orgs.). 20I4. Cómo repensar el desarrollo productivo? Políticas e instituciones sólidas para la transformación económica. Washington: BID.

Desiderá Neto, W. A. (org.). 20I4. O Brasil e novas dimensões da integração regional. Rio de Janeiro: Ipea.

Desiderá Neto, W. A., e Teixeira, R. A. (orgs.). 2012. Perspectivas para la integración de América Latina. Brasília: Ipea.

Gehre, Thiago. 2009. América do Sul: a ideia brasileira em marcha. Curitiba: Juruá.

Giordano, Paolo (org.). 2015. La recaída: América Latina y el Caribe frente al retroceso del comercio mundial. Monografia del BID. 2015. https://publications.iadb.org/bitstream/handle/II3I9/7243/Monitor-20I5-La-reca\%C3\%ADda-Am\%C3\%Agrica-Latina-y-el-Caribe-frente-al-retroceso-del-comercio-mundial.pdf

Martins, Estevão Chaves de Rezende (org.). 2003. Relações internacionais: visões do Brasil e da América Latina. Brasília: Ibri. 
Mellado, Noemi B. (org.). 20I5. Estrategias de inserción internacional e integración latinoamericana en el siglo XXI. Córdoba: Lemer.

Moreira, L. F. et al. 20ıо. As relações internacionais da América Latina. Petrópolis: Vozes.

Nasser, R. M., e Moraes, R. F. de (orgs.). 20I4. O Brasil e a segurança no seu entorno estratégico. Brasília: Ipea.

Novelo, Federico. 20I4. El desarrollo económico y social en América Latina: El doble atraso. México: Cepal.

Otero, Delia del Pilar. 2007. Integración latino-americana. Córdoba: Alción.

Patrício, Raquel de Caria. 20I2. Estudos de área: América Latina - uma visão de América Latina. Lisboa: Universidade Técnica de Lisboa.

Ray, Rebecca et al. (orgs.). 2015. China in Latin America : lessons for SouthSouth cooperation and sustainable development. Boston: Boston University-BID Intal.

Resende, S. M., e Mallman, M. I. (orgs.). 20I3. Mercosul 21 anos: maioridade ou imaturidade. Curitiba: Appris.

Ruiz, José Briceño, e Simonoff, Alexandro. 2015. Integración y Cooperación Regional en América Latina. Buenos Aires: Biblos.

Sánchez-Mais, Luis. 20I5. Ensayo sobre una política alternativa para el desarrollo latino-americano. Caracas: CAF.

Sevares, Julio. 20Iо. Por qué crecieron los países que crecieron. Buenos Aires: Edhasa.

Soria, Adrián Bonilla et al. (orgs.). 2015. Iberoamérica: miradas estratégicas en el siglo XXI. San José: Flacso.

Unasur. 20I4. Ciencia, tecnología, innovación e industrialización en América del Sur: hacia una estrategia regional. Quito: Unasur.

Vidigal, Carlos Eduardo. 200I. "Integração Brasil-Argentina: o primeiro ensaio (I958-1962).” Dissertação de Mestrado, Universidade de Brasília, Brasília.

Vidigal, Carlos Eduardo. 2009. Relações Brasil-Argentina: a construção do entendimento (1958-1986). Curitiba: Juruá.

Xing, Li, e Christensen, Steen F. (orgs.). 20I2. The rise of China: the impact on semi-periphery and periphery countries. Aalborg: Aalborg University Press. 


\section{RESUMO}

A última década do século XX caracterizou-se por duas mudanças profundas nos países da América Latina. O velho paradigma desenvolvimentista, esgotado, cedeu lugar ao paradigma neoliberal, abraçado com entusiasmo por dirigentes e sociedades latino-americanos. Ao transitar para o século XXI, a região passa por nova mudança paradigmática: exauriu-se no espaço de uma década a dinâmica neoliberal, e os países da América Latina mergulharam no século XXI à procura de outro destino.

\section{PALAVRAS-CHAVE}

América Latina; Século XXI.

Recebido em 22 de julho de 2016. Aprovado em 27 de julho de 2016. 